\title{
Role of Intelligence Transport System in the Fight against Road Accidents in Kenya
}

\author{
Jackson Mwiti Isaiah \\ School of Computing \& Informatics \\ Meru \\ University of Science and \\ Technology, Kenya
}

\author{
E. Abande, $\mathrm{PhD}$ \\ School of Computing and \\ Informatics, \\ University of Nairobi, Kenya
}

\author{
Mutua Stephen, PhD \\ School of Computing \& Informatics \\ Meru \\ University of Science and \\ Technology, Kenya
}

\begin{abstract}
Accidents continue to claim many lives due to human errors that can be avoided by application of technology. Application of intelligent transport systems (ITS) in the Transport industry has gained momentum and some government funded projects have been rolled out in countries like United States, United Kingdom, and Canada among others. However, ITS projects can be very costly and unattainable to developing countries if the right approach is not followed. Perhaps, this explains the reason why many developing countries are yet to embrace the use of ITS despite reporting among the highest road accidents. This paper presents a review on ITS and solutions they can offer in reducing road accidents in developing countries with a focus of Kenya. This study assesses the impact of intelligent transportation systems in alleviating road accidents. Motivation behind this research is to identify ways in which application of ICT can be applied through affordable and effective ways to help the government and other transport stakeholders in getting a solution to the problem that are affecting the society. A review of intelligent transport systems shows that if they can be effectively applied, accidents can be greatly reduced.
\end{abstract}

\section{General Terms}

ITS, GPS, Transport, Accidents

\section{Keywords}

Transportation system, Accident, Safety, Human Error, Intelligent Transport Systems

\section{INTRODUCTION}

Road accidents continue to claim lives in Kenya daily [28]. These accidents have been exerting pressure on the economy in terms of hospital cost as well as insurance companies that are collapsing due to endless claims every time. Families continue to bear the brunt of these accidents due to lost incomes of the bread winner as well as the society due to loss of production. Based on the National transport and Safety Authority of Kenya (NTSA), there has been an increase of road accidents over the past years. Rise in accidents can be attributed due to the rise in numbers of vehicles in Kenya over the last decade [2]. An accident can be as a result of many factors, but in most cases, the transport industry stakeholders blame the poor state of Kenyan roads as the leading cause of accidents [22].

According to Kenyan police statistics, cases of accidents due to overtaking accounts to $44 \%$ of all accidents recorded by the year 2017[30]. During overtaking, most drivers, who are involved in road accidents overtake regardless of whether there is any oncoming vehicle or not. Most roads accidents occur as a result of the driver not knowing whether there is any oncoming vehicle or not. In such a situation, challenge is brought by the vehicle following from behind which in most cases is caught unaware by the overtaking driver trying to come to her lane after sensing danger.

From the recent findings, Road traffic injuries in Kenya are a many bearing in mind the state of the neglected public health sector which presents a challenge that requires concerted efforts for effective and sustainable prevention.

With so many accidents occurring every day, the government of Kenya through the respective ministry has been at the forefront employing measures to reduce these accidents. Through the ministry of transport (MOT) an action plan has been prepared whereby measures such as launching of campaign to create awareness [20]. Safety on the road has always been an issue, but today due to the continuously growing number of vehicles, the number of accidents also increases and the need for better safety systems becomes essential [9].

With all these efforts accidents continue to be reported on our major highways and roads which has not gone unnoticed by researchers who are undertaking research works on how technology can play a role in minimizing the number of accidents. The use of intelligent transport systems (ITS) has been proposed as a potential remedy to this challenge. This technology is aimed at increasing safety, improve the transportation infrastructures, and provide critical safety information to road users ([18].

GPS systems have been proposed due to their ability to accurately identify the vehicle location and this can used in creating collision avoidance systems [31]. However, GPS systems have not gone without showing some undesired problems such as not always being available or not being robust enough for some applications [8].

This type of system was developed by Colorado School of mine [3]. This system was installed with GPS and wireless network and 3D technology to help the driver avoid rolling over the edges of dumpsites which were causing many accidents. This system could track the vehicle in respect to the edges of dumpsite as well as to warn the driver of the close proximity or collision. However wireless networks would be very expensive as would involve erecting communication device on everywhere on the road.

Inter vehicle communication has generated a lot of interest to researchers on its role in design of Intelligent Transport systems. Vehicular Ad hoc Network (VANET) enables vehicles to communicate with one another as they move on the road[32].

Many researchers have contributed to this idea but very little has been done on addressing the challenge that comes with VANET. The challenge of vehicle of very few vehicles on the road affects the network reliability. 


\section{ROAD ACCIDENTS}

Road accidents in Kenya are one of the major causes of deaths in the country. Road traffic injuries (RTIs) are one of the leading causes of death and disability worldwide [21]. The increase in road accidents can be attributed by sharp increase in the number of registered motor vehicles over the past two decades - from 1.4 motor vehicles per 100 people in 1985 to 2.7 motor vehicles per 100 people in 2007 [23],[5]. According to World Bank report, more than one million people die in road crashes per year. $85 \%$ of these deaths occur in developing countries and it is predicted that the number of road accidents will continue to rise unless something is done.

Between 3000 and 13000 Kenyans lose their lives in road traffic crashes every year(WHO) A lot of attention has been put curving road accidents resulting from fatigue, un roadworthy vehicles, drunkenness, but very little is being made on accidents resulting from poor overtaking.

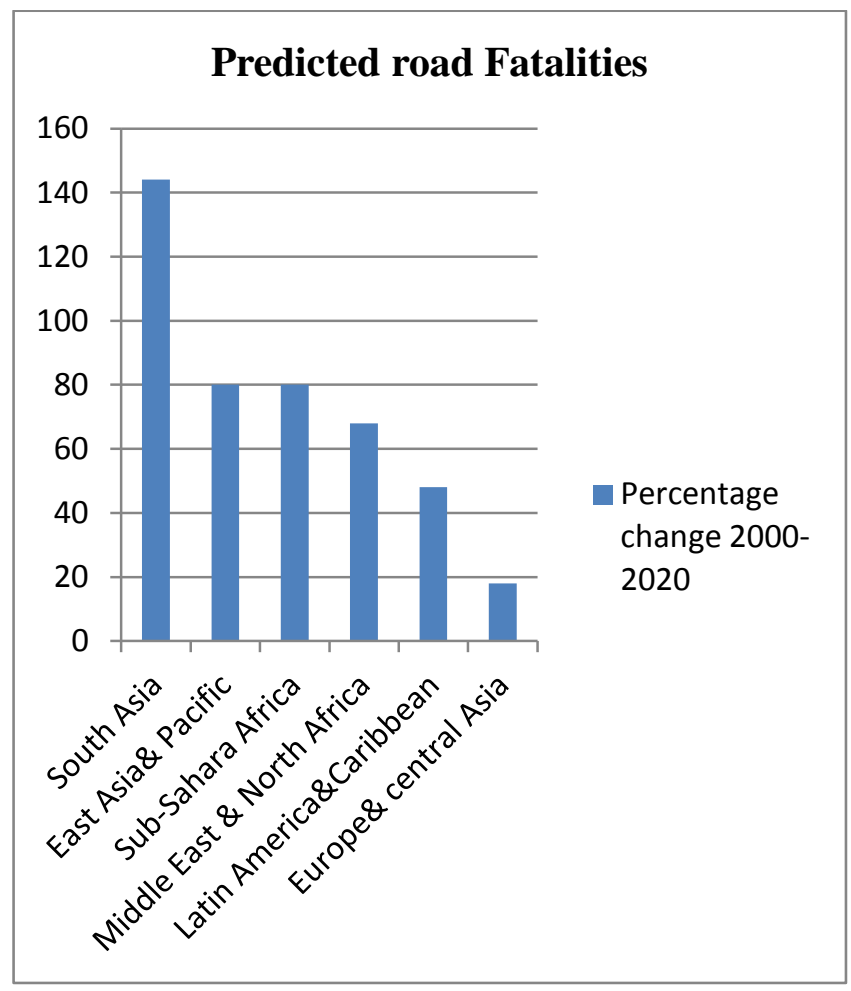

Fig 2:Source: World Bank [33]

\section{THEORETICAL CONCEPTION OF ROAD TRANSPORT AND SAFETY}

According to [14], the efficiency and safety of road transport depends on the strength of its supportive functional pillars, which in turn depend on the strength of their institutional foundations. Road transport remains an important sector of the economy which interconnects all sectors of the economy [14].The strength of each of the institutional foundations also depends on the extent to which they embrace stakeholder involvement and participation in their activities

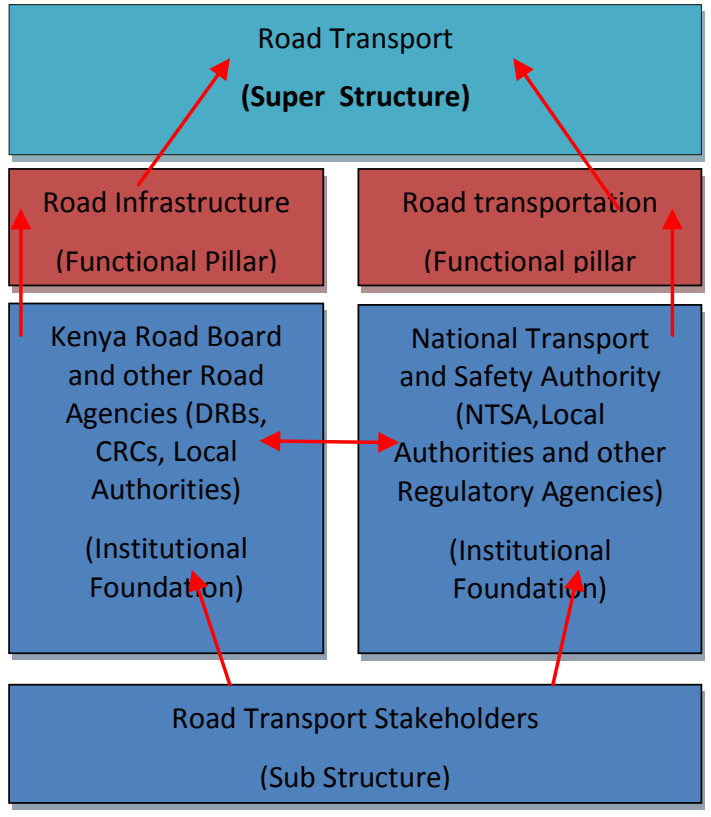

Fig 3: Source: [14] Structural-Functional linkages in Kenya's Road Transport Sector

\section{METHODOLOGY}

The standard systematic literature review method was employed to collect data, appraise, select and synthesize the literature. Data was collected using a manual search from the IEEE, ACM and google scholar. The former two were considered to be the leading technology based journals whereas the latter was used to integrate any other high impact journal articles which may have been published outside the two. The keywords identified in this review were "intelligent transport" and "review". These were further refined using the time of publication, journal impact factor and inclusion of the keyword "developing nation" and finally "Kenya".

\section{ANALYSIS}

On google scholar, the total results returned were 28,100 . These were further refined based on the time of publication giving the results presented in Figure 4.1 which indicated an exponential growth of interest in ITS over the last two decades. With a mean of 1109 articles per year, it is clear that the area of ITS has seen more activity in the last one decade and is likely to see growing interests as indicated by the number of articles (450) in the first one and half months of the year 2019. Similarly, refinement was enhanced using the keywords "Kenya" resulting into 512 articles which were further reduced to 328 to comprise only those which were published between 2013 and 2019. In assessing the use of ITS in accidents, the keyword "accident" was included in the Kenyan perspective, the search resulted to 101 articles which were all acquired and their relevance assessed 


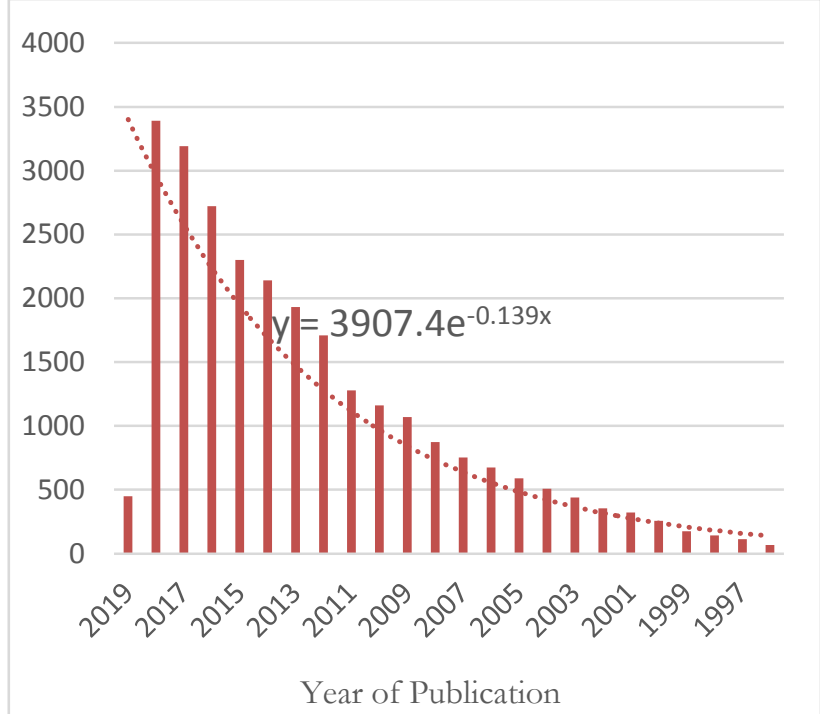

Fig 4: Exponential growth in number of publications on ITS over the last two decades

All these results were consolidated as reflected in the Venn diagram illustrated in figure 4 .

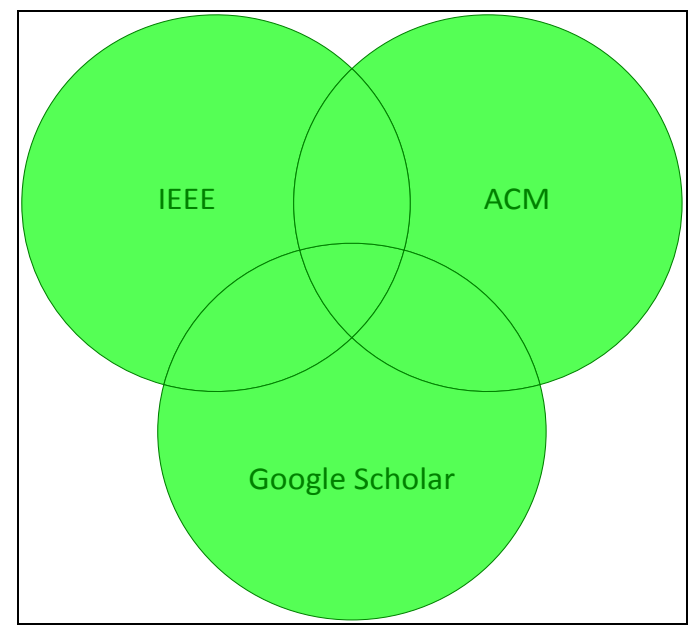

Fig 5:Venn Diagram showing distribution of Journal Articles from google scholar, IEEE and ACM

Based on these fetched articles, the impact of ITS in alleviating road accidents was then assessed based on main leading causes of accidents in developing countries as detailed in the following subsections.

\section{CAUSES OF ROAD ACCIDENTS}

The principal contributing factors of road accidents are human errors, adverse, road environment, dangerous overtaking, reckless driving, carelessness of road users, failure to obey mandatory traffic regulations. Most of these causes are as a result of human error[24].

\subsection{Human Errors}

According to [25], the research shows that human error accounts to over $75 \%$ of all road crashes that are recorded. [24] Defines human error as a "generic term to encompass all those occasions in which a planned sequence of mental or physical activities fails to achieve its intended outcome, and when these failures cannot be attributed to the intervention of some chance agency". Drivers in most cases make judgment error due to unavailable information to help them make informed choices.

In his books titled "Why Human Error Causes Accidents",[4], argues that everyone makes mistakes and Human errors are part of our everyday experience. He further defines human error as 'someone making a mistake'. He continues to say that human error to occur within an action, the action must be accompanied by an intention to achieve a desired result or outcome. In most cases driver aim is to overtake a vehicle regardless of the situation ahead. Overtaking is an action that many drivers error and therefore there is a need to help at this task.

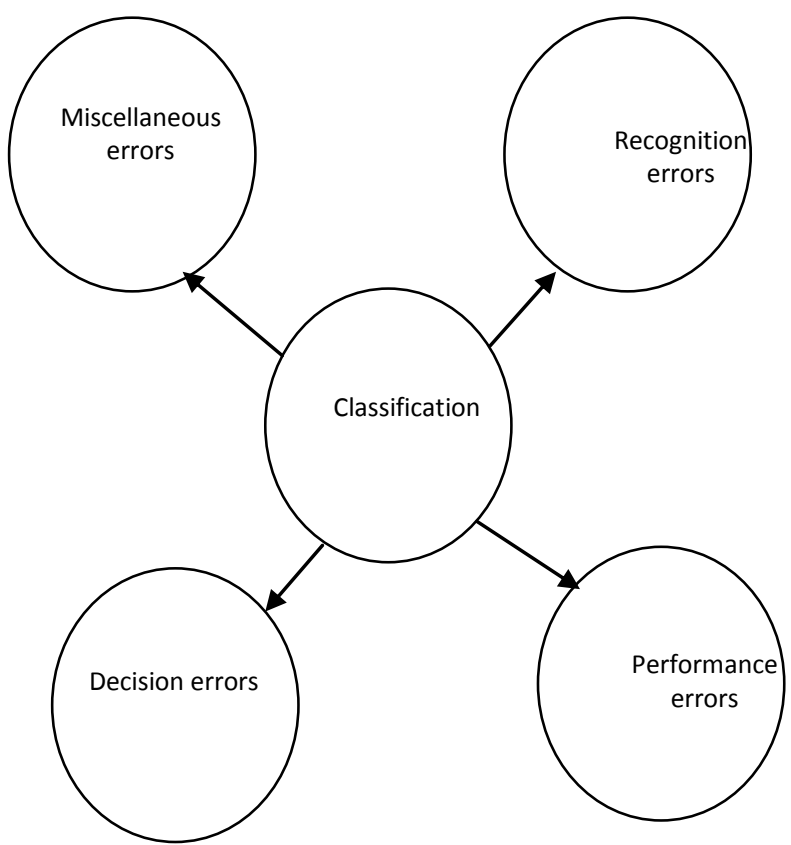

Fig 6: Types of human error that can result in accident Source: [24]

[4]analysis the task and human capability where he says that one way of making the judgment is to assess whether the external environment or stimulus to action seems conducive to reasonable performance, given the capabilities of the person undertaking the task.

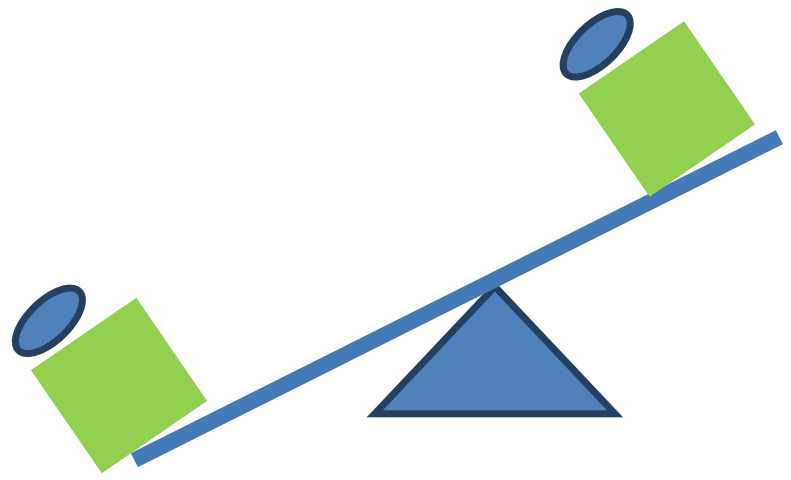

Task demand Human Capability

Fig 7: The balance between human capability and task demand: Source: [4] 
Most drivers make judgments on the bases of luck which in most cases becomes very costly. The task of knowing what lies ahead is enormous and beyond human capability.

Driver behavior plays a significant role in the occurrence of lane change collisions [4]. Traffic accident statistics or safe driving, a driver is in the center of the safety analysis, driver response delay together with other factors restricts the driving path of a vehicle [19]. The life of the persons in a vehicle depends on the driver's reaction to sudden events, such as the appearance of a traffic jam end [9]. The driver will always experience a deficit in the expectations if the subjectively perceived information does not correspond to the full picture of the driving environment [10]. According to [18] human causes of lane change collisions can be classified into two major categories:

- Recognition errors, including inattention, external distraction, and improper lookout.

- Decision errors, including false assumption, improper maneuver, and improper driving technique.

\subsection{Overtaking}

Overtaking is the second highest cause of road accidents [18]. Driver might decide to overtake a vehicle due to a number of reasons. A very slow vehicle might make the driver want to overtake if the driver is in hurry and the road ahead is clear. Another reason that may make the driver want to overtake is when there is a stationery vehicle on the road. Overtaking involves lane change. Lane change takes place when a vehicle moves from an originating lane to a destination lane[18].

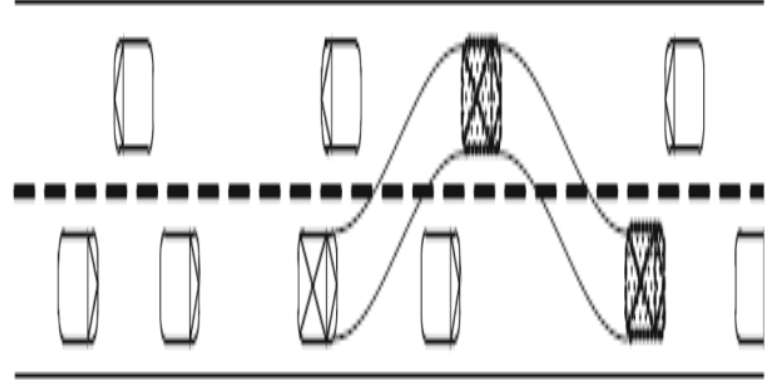

Fig: Source: [18] overtaking in opposing traffic .

\subsection{Driving Environment}

Driving environment is another major cause of road accidents. For the driver to drive a vehicle well, he needs accurate information about the driving environment in addition to wellfounded training, experience and the ability to perform routine functions [10]. The surrounding determines the environment. Driving environment is based on the position, movement and type of the other vehicles on the road, and on the other hand on the route and the nature of the road, on traffic regulations, weather, visibility [10].

\subsection{Role Intelligent Transportation in alleviating road accidents}

With Technology today, modern vehicles are being equipped with equipment that assist driver on the road and make the driving safe and comfortable. The Intelligent Transportation Systems (ITS) is designed to maximize mobility of the vehicle, safety of the occupants and road users [11]. Literature has shown that many accidents are as a result of human error. ITS help in situation that cause collisions due to error, poor communications, signaling difficulties and environmental conditions such as visibility [15]. ITS main aim is to broaden the range of driver perception his or her field of vision.

ITS make use of technologies such as Global Positioning System (GPS), wireless ad-hoc network. In most cases, sensors are used for sensing the state and mapping the environment surrounding the vehicle, among them[12]. Today, ITS are being applied to support the driver in controlling his/her vehicle in a better way (Advanced Driver Assistance Systems (ADAS), systems that support the traveller in finding an optimal mode and route, (Advance Traveller Information Systems (ATIS) and systems that are concerned with a more efficient organization of traffic flows throughout the existing road infrastructure network (Advanced Traffic Management Systems (ATMS)[13].

The emergent of ITS has brought about intelligent vehicles which are enhanced with perception, reasoning, and actuating devices that enabling the automation of driving tasks like safe lane following, avoiding obstacles as well as overtaking slower traffic avoiding dangerous situations[1]. An intelligent vehicle is able to assess the driving scenario and react in case of danger would allow up to $90 \%$ of traffic accidents that are caused by human errors to be eliminated, saving human lives [1]. Most vehicles today are coming with embedded computing systems which are increasingly making them safer as well as more reliable, comfortable, and enjoyable to drive [26].

An intelligent assistant is a concept derived from artificial intelligence that identifies a kind of systems whose role is to assist the user in decision-making processes. This type of systems emphasizes that the operator is the final responsible of decisions, so the system is not designed to substitute the operator but, on the contrary, its goal is to provide services for assistance such as: information filtering and interpretation to identify significant data, what if analysis, justification of conclusions [2].

\subsection{Non-autonomous Systems}

Non-autonomous Systems are systems that prevent accidents with the help of an inside vehicle warn system and only announce the danger to the driver. These systems are based on one-way permanent beacon messages [9].

When a vehicle makes a prediction of a collision, it warns the driver visually, auditory, and or haptic. If the system expects that the driver still has enough time to avoid a crash, it will not attempt to control the vehicle [9]. The control of the vehicle remains purely driver responsibility. This type of systems wills only advice the driver on the dangers on the road. These systems rely on the roadside infrastructure and on-board sensors to inform the driver about the environment. If a collision is imminent, the driver is warned to take appropriate action. It provides assistance to the driver primarily to avoid rear-end collisions with other vehicles [9].

The ITS will enable the driver get to deal with environmental situations. While overtaking ITS will play a major role in advising the driver to make appropriate decision. All these are towards controlling the vehicle and the final decision making rest with the human driver. 


\section{CONCLUSION}

Intelligent transport system has role to play in reducing road accidents all over the world. From the literature, we can conclusively say that intelligent transport systems if adopted by the Kenyan Government can greatly reduce the road accidents which have continued to rob the society the working class as well as the bread winners . Therefore, it is recommend that the ministry concerned to take up the challenge and embrace this technology since all other methods have not been successful so far.

\section{ACKNOWLEDGMENTS}

We do acknowledge our colleagues for their word of advice during the compilation of this paper. Finally, we greatly thank Meru University of Science and Technology and University of Nairobi whose resources were used for the putting this work together.

\section{REFERENCES}

[1] Alberto Broggi, Alexander Zelinsky, Michel Parent, Charles E. Thorpe- intelligent vehicles- Springer Handbook of Robotics (2008)

[2] An Intelligent Assistant for Public Transport Management Martin Molina Department of Artificial Intelligence, Universidad Politécnica de Madrid, Advances in Intelligent Computing, 2005 - Springer

[3] Nieto, A., \&Dagdelen, K. (2003). Development and testing of a vehicle collision avoidance system based on GPS and wireless networks for open-pit mines. Application of Computers and Operations Research in the Minerals Industries.

[4] Whittingham, R.B., The Blame Machine: Why Human Error Causes Accidents, Elsevier ButterworthHeinemann, Oxford, U.K., 2004.

[5] Odero, W., Khayesi, M. and Heda, P.M. 2003 Road traffic injuries in Kenya: Magnitude, causes and status. In: Injury Control and Safety Promotion, Vol.10 (1-2)

[6] ZuzanaBělinová, PetrBureš, and Peter Jesty*Intelligent Transport System Architecture Different Approaches and Future Trends Data and Mobility, AISC 81, pp. 115125, 2010. springerlink.com $\odot$ Springer

[7] H.C Tseng, P.P Tu, Y.C Lee and Ts Wang Study of satellite navigation fleet management system usage in Taiwan with application of C-TAM-TPB Model. 2013 Asian Network for Scientific information

[8] Boukerche, A., Oliveira, H. A., Nakamura, E. F., \&Loureiro, A. A. (2008). Vehicular ad hoc networks: A new challenge for localization-based systems. Computer communications, 31(12), 2838-2849

[9] Popescu-Zeletin, R., Radusch, I., \&Rigani, M. A. (2010). Vehicular-2-X communication: state-of-the-art and research in mobile vehicular ad hoc networks. Springer Science \& Business Media.

[10] Loewenau, J., Gresser, K., Wisselmann, D., Richter, W., Rabel, D., \&Durekovic, S. (2006). Dynamic Pass Prediction-A New Driver Assistance System for Superior and Safe Overtaking.In Advanced Microsystems for Automotive Applications 2006 (pp. 67-77).Springer Berlin Heidelberg.

[11] Suh, W., Chang, K., \& Lee, E. (2011). Towards reliable intelligent transportation systems for e-government. In
Electronic Government and the Information Systems Perspective (pp. 299-314). Springer Berlin Heidelberg.

[12] Merzouki, R., Samantaray, A. K., Pathak, P. M., \&Bouamama, B. O. (2012). Intelligent Mechatronic Systems: Modeling, Control and Diagnosis. Springer.

[13] Argiolu, R., van der Heijden, R., \&Marchau, V. (2007). ITS-Based Transport Concepts and Location Preference: Will ITS Change 'Business as Usual'?.In Essays on Transport Economics (pp. 293-315).Physica-Verlag HD.

[14] Asingo, P. Q., \&Mitullah, W. (2007). Implementing Road Transport Safety Measures in Kenya.Working Paper 545. IDS: University of Nairobi.

[15] Singh, S., Nelakuditi, S., Roy Choudhury, R., \& Tong, Y. (2012, June). Your smartphone can watch the road and you: mobile assistant for inattentive drivers. In Proceedings of the thirteenth ACM international symposium on Mobile Ad Hoc Networking and Computing (pp. 261-262). ACM.

[16] Reason, J., Manstead, A., Stradling, S., Baxter, J., \& Campbell, K. (1990). Errors and violations on the roads: a real distinction?. Ergonomics, 33(10-11), 1315-1332.

[17] Tran, C., \&Trivedi, M. M. (2011). Vision for driver assistance: Looking at people in a vehicle. In Visual Analysis of Humans(pp. 597-614). Springer, London.

[18] Lane Change and Overtaking Collisions: Causes and Avoidance Techniques Jing Bie, Mark Roelofsen, Lisheng Jin and Bart van Arem R. Naja (ed.), Wireless Vehicular Networks for Car Collision Avoidance, DOI: 10.1007/978-1-4419-9563-6_6,___ Springer Science+Business Media New York 2013

[19] Cheng, H. T., Shan, H., \&Zhuang, W. (2011). Infotainment and road safety service support in vehicular networking: From a communication perspective. Mechanical Systems and Signal Processing, 25(6), 20202038.

[20] efforts to improve road safety in kenya achievements and limitations of reforms in the matatu industry by preston o. Chitere and Thomas N. Kibua Institute of Policy Analysis and Research (IPAR) (2005)

[21] Bachani, A. M., Koradia, P., Herbert, H. K., Mogere, S., Akungah, D., Nyamari, J., ...\& Stevens, K. A. (2012). Road traffic injuries in Kenya: the health burden and risk factors in two districts. Traffic injury prevention, 13(sup1), 24-30.

[22] Muchene, L. K. (2013). Road accidents in Kenya: a case of poor road network or human error?.Universiteit Hasselt, Diepenbeek. Retrieved May, 31, 2016.

[23] Assum, T. (1998). Road safety in Africa: appraisal of road safety initiatives in five African countries. In The World Bank and United Nations Economic Commission for Africa, 1998 (Working Paper No. 33). 2. THE GLOBAL IMPACT 67 .

[24] Dhillon, B. S. (2007). Human Error in Road Transportation Systems. Human Reliability and Error in Transportation Systems, 105-116.

[25] Human error and road transport by paul Salmon, Michael Reagan,Ian Johnston Monash University accident research centre (2005) 
[26] Vision for Driver Assistance:Looking at People in a Vehicle-Cuong Tran and Mohan ManubhaiTrivedi- T.B. Moeslund et al. (eds.), Visual Analysis of Humans, DOI 10.1007/978-0-85729-997-0_30, (C) Springer-Verlag London Limited 2011

[27] Singh, J., Desai, A., Acker, F., Ding, S., Rachide, A. A., \& Nelson-Furnell, P. (2013). Multi-Modal Cooperative Intelligent Transport Systems to Improve Safety.In Advanced Microsystems for Automotive Applications 2013 (pp. 55-66).Springer International Publishing.

[28] https://www.nation.co.ke/news/Night-horrors--Concernas-road-crashes-claim-hundreds-of-lives/1056-4915458q5k27ez/index.html

[29] http://www.ntsa.go.ke/index.php?option=com_content\& view $=$ article $\& \mathrm{id}=213 \&$ Itemid $=706$
[30] https://www.nextinsurance.co.ke/blog/road-accidents-inkenya-stats-types-causes-car-accident/

[31] Borker, S., \&Lohani, R. B. (2010, September). A Low Cost GPS Based Vehicle Collision Avoidance System. In International Conference on Advances in Information and Communication Technologies (pp. 619621).Springer, Berlin, Heidelberg.

[32] Toor, Y., Muhlethaler, P., Laouiti, A., \& De La Fortelle, A. (2008). Vehicle ad hoc networks: Applications and related technical issues. IEEE communications surveys \& tutorials, 10(3), 74-88.

[33] https://www.who.int/violence_injury_prevention/publicat ions/road_traffic/world_report/chapter2.pdf 